\title{
Sebaran Aktivitas Radionuklida Alam dalam Sedimen di Perairan Sluke Rembang, Jawa Tengah
}

\author{
Jarot Marwoto', Muslim", Zanet Dwi Aprilia', Purwanto' dan Murdahayu Makmur² \\ 'Departemen Oseanografi, Fakultas Perikanan dan Ilmu Kelautan, Universitas Diponegoro \\ JI. Prof. Soedarto, SH. Kampus UNDIP Tembalang, Semarang 50275 \\ 2Kelompok Radioekologi Kelautan, Pusat Teknologi Keselamatan dan Metrologi Radiasi, \\ Badan Tenaga Nuklir Nasional, \\ Jl. Lebak Bulus Raya No. 49, Kotak Pos 7043, Jakarta Selatan 12070, Indonesia \\ Email: aqua_muslim@yahoo.com
}

\begin{abstract}
Distribution of Natural Radionuclides in Sediment in the Sluke Waters of Rembang, Central Java

The existence of natural radionuclides has been around since the earth was formed. Steam Power Plant in Sluke Rembang is operated by coal fuel that produces some natural radionuclides that release as a gas through the chimney to atmosphere. These radionuclides fall on the land and sea. The purpose of this study was to know the activity of gamma-emitting natural radionuclides in sediments and its distribution in the Sluke waters of Rembang. The result showed that activity of $40 \mathrm{~K}$, $212 \mathrm{~Pb},{ }^{226} \mathrm{Ra}$ dan ${ }^{228} \mathrm{Ac}$ appeared fluctuating with a range from 160.54-503.87 Bq/kg; 88.62-333.34 $\mathrm{Bq} / \mathrm{kg} ; \quad 66.07-95.24 \mathrm{~Bq} / \mathrm{kg}$ and $95.30-466.46 \mathrm{~Bq} / \mathrm{kg}$ respectively. The distribution of natural radionuclides was affected by topography, resources and the movement patterns of currents that move from the source of radionuclides to the northeast. The data obtained in this study will serve as baseline data in natural radionuclide in Sluke, Rembang.
\end{abstract}

Keywords: Natural radionuclides; Steam Power Plant; Current patterns; Sluke waters

\begin{abstract}
Abstrak
Keberadaan radionuklida alam sudah ada sejak bumi terbentuk. Pusat Listrik Tenaga Uap (PLTU) di Sluke Rembang dioperasikan dengan bahan bakar batu bara yang menghasilkan beberapa radionuklida alam dalam bentuk gas yang dilepaskan melalui cerobong asap ke atmosfir. Radionuklida tersebut akhirnya jatuh di darat dan di perairan laut. Penelitian ini bertujuan untuk mengetahui aktivitas radionuklida alam dalam sedimen dan distribusinya di perairan Sluke, Rembang. Hasil penelitian menunjukkan nilai aktivitas radionuklida alam ${ }^{40 \mathrm{~K}}, 212 \mathrm{~Pb}, 226 \mathrm{Ra}$ dan ${ }^{228} \mathrm{AC}$ berfluktuasi, secara berturut-turut adalah dari 160,54-503,87 Bq/kg; 88,62-333,34 Bq/kg; 66,07-95,24 $\mathrm{Bq} / \mathrm{kg}$ dan $95,30-466,46 \mathrm{~Bq} / \mathrm{kg}$. Distribusi aktivitasnya dipengaruhi oleh topografi, sumber dan pergerakan pola arus yang bergerak dari sumber radionuklida menuju ke timur laut. Hasil penelitian ini dapat digunakan sebagai baseline unsur radionuklida alam (NORM) di Sluke Rembang.
\end{abstract}

Kata Kunci: Radionuklida alam; PLTU; Pola arus; Perairan Sluke

\section{PENDAHULUAN}

Radinuklida alam atau yang biasa disebut dengan NORM (Naturally Occuring Radioactive Material) merupakan zat yang memancarkan radiasi secara alami di lingkungan dan telah berlangsung selama 4,5 milyar tahun sejak terbentuknya bumi.
Sumber NORM berasal dari luar angkasa (cosmis) dan tanah (soil) (Maher dan Saleh, 2007). Aktivitas dan sebaran NORM di lingkungan khususnya di sedimen laut perlu dipelajari, karena unsur-unsur tersebut akan masuk dalam suatu kehidupan organisme yang akhirnya berpengaruh pada manusia melalui rantai makanan (UNSCEAR, 2008), 
sehingga penting untuk evaluasi resiko kesehatan manusia (El-Taher and Madkour, 2011). Jadi bila suatu wilayah ada sumber NORM, maka sangat perlu dilakukan monitoring, karena akan mengakibatkan pendistribusian NORM menjadi luas dan mudah mengalami peningkatan aktivitas (Cooper, 2005).

\section{PLTU Sluke-Rembang adalah PLTU}

(Pusat Listrik Tenaga Uap) yang menggunakan bahan bakar batu bara berkalori rendah sebagai pengganti BBM. Setiap tahunnya membutuhkan sekitar 2,16 juta ton batu bara (Modesta, 2008). Menurut Uslu dan Gökmeşe (2010), operasional PLTU batubara mengeluarkan abu layang (fly ash dan bottom ash) dari hasil pembakaran. Aktivitas bongkar muat kapal tongkang yang membawa batu bara juga menyisakan reruntuhan batubara yang jatuh saat pembongkaran menuju tempat penyimpanan (stockfile). Cooper (2005) telah mendapatkan bahwa pemakaian batu bara dapat mengakibatkan peningkatan aktivitas radionuklida berupa Uranium (<1\%) dan Thorium sekitar $6 \%$ yang berpotensi meradiasi manusia (Coles et al., 1978).

Sihono et al., (2012) telah melakukan penelitian dengan mengambil sampel udara dan menyatakan bahwa PLTU Rembang mengeluarkan radionuklida ${ }^{234} \mathrm{Th}, 226 \mathrm{Ra}, 212 \mathrm{~Pb}$, ${ }^{208} \mathrm{Tl}, 214 \mathrm{~Pb},{ }^{214} \mathrm{Bi}$ dan ${ }^{40} \mathrm{~K}$ dengan nilai aktivitas berkisar antara 3-6 $\mathrm{Bq} / \mathrm{m}^{3}$. Radionuklida dari abu layang akan jatuh ke perairan Sluke dan disebarkan oleh arus laut. Arus laut mempengaruhi adanya resuspensi sedimen melalui proses turbulensi yang akan mengakibatkan pelepasan aktivitas radionuklida dalam sedimen.

\section{MATERI DAN METODA}

Penentuan lokasi didasarkan dengan purposive sampling method yaitu metoda penentuan lokasi yang dipilih dengan cermat sehingga stasiun-stasiun yang dipilih mewakili perairan Sluke, Rembang sebagai daerah penelitian. Adapun pertimbangan yang dipakai adalah berdasarkan daerah yang mewakili pantai (Stasiun 1 dan 9); daerah peralihan antara daerah pantai dan lepas pantai (Stasiun 2, 3, 7 dan 8), dimana stasiun 2 merupakan daerah dekat ekosistem mangrove; daerah lepas pantai (Stasiun 4, 5 dan 6), dimana stasiun 5 merupakan daerah pembongkaran muatan batubara. Jadi penentuan lokasi dipilih oleh penulis menurut ciri-ciri spesifik dan karakteristik tertentu (Djarwanto dan Subagyo, 1998). Lokasi masing-masing satsiun sampel dapat dilihat pada Gambar 1.

Sampel sedimen sebanyak sekitar $2 \mathrm{~kg}$ per stasiun diambil dengan menggunakan sedimen grab. Sebelum dianalisa tingkat aktivitasnya, sampel sedimen dikeringkan dengan panas sinar matahari, kemudian

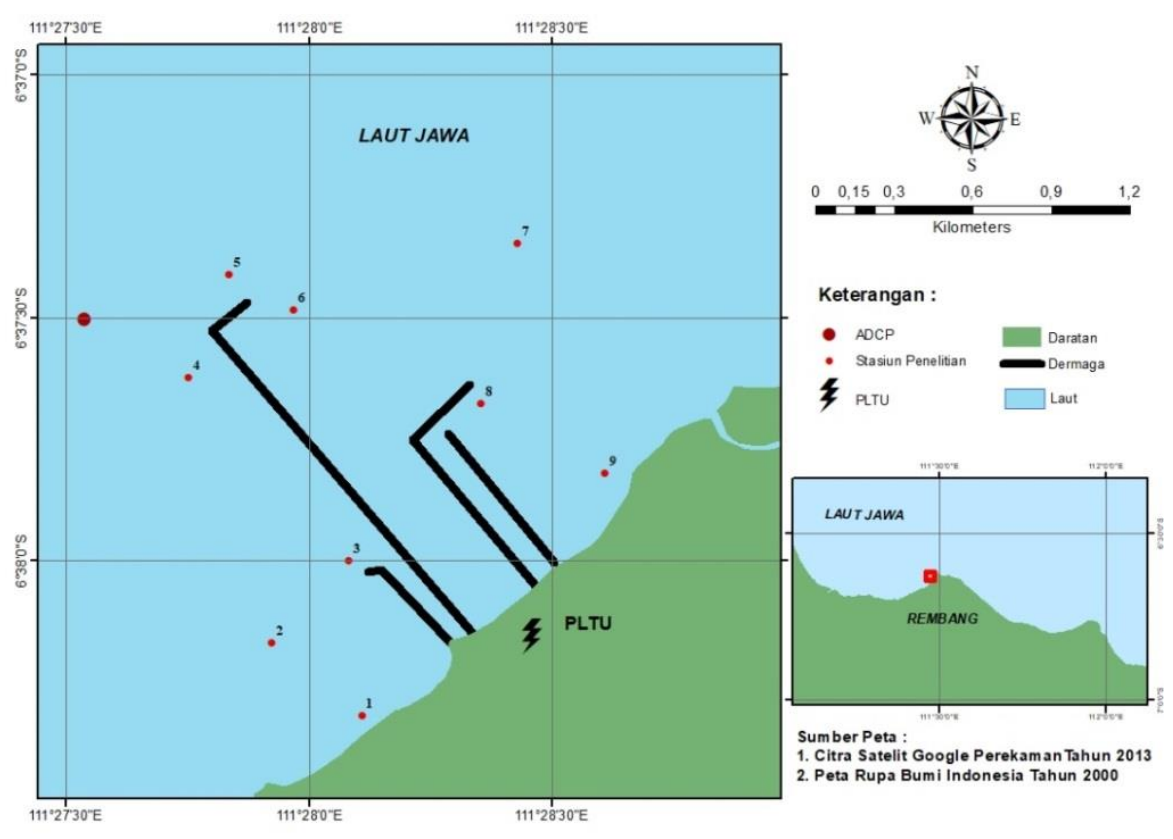

Gambar 1. Lokasi Penelitian 
untuk menghilangkan kandungan airnya dikeringkan dengan oven pada temperatur $100{ }^{\circ} \mathrm{C}$. Selanjutnya sedimen dihomogenkan dengan menggunakan grinder tipe Fritsch dengan Ukuran $50 \mu \mathrm{m}$. Sampel sedimen sebanyak 1000gram diambil dan dimasukkan kedalam Marinelli untuk dihitung aktivitasnya. Pengukuran aktivitas sampel dengan spektrometer gamma dilakukan selama 72 jam (3 hari).

Pengukuran data arus dilakukan dengan menggunakan ADCP (Acoustic Doppler Current Profiler) yang dapat merekam data secara otomatis. Prinsip kerja ADCP menggunakan teknik euler yaitu pengamatan data arus pada lokasi yang tetap (Poerbandono dan Djunasjah, 2005). Data yang diperoleh meliputi kecepatan dan arah arus. Pengukuran atau perekaman data arus dilakukan pada kedalaman 10 meter. Hasil pengamatan data arus ADCP digunakan untuk verifikasi dengan data satelit hasil pembacaan software Ferret.

\section{HASIL DAN PEMBAHASAN}

Hasil analisa radionuklida alam pada 9 titik pengambilan sampel didapatkan nilai aktivitas NORM yang fluktuatif, dimana nilai aktivitas $40 \mathrm{~K}$ berkisar dari 160,54-503,87 Bq/kg dengan nilai rata-rata $365,79 \mathrm{~Bq} / \mathrm{kg} ; 212 \mathrm{~Pb}$ berkisar dari $88,62-333,34 \mathrm{~Bq} / \mathrm{kg}$ dengan nilai rata-rata $162,01 \mathrm{~Bq} / \mathrm{kg}$; ${ }^{226} \mathrm{Ra}$ berkisar dari $66,07-95,24 \mathrm{~Bq} / \mathrm{kg}$ dengan nilai rata-rata 76,70 $\mathrm{Bq} / \mathrm{kg}$ dan ${ }^{228} \mathrm{Ac}$ berkisar dari $95,30-466,46$ $\mathrm{Bq} / \mathrm{kg}$ dengan nilai rata-rata $216,02 \mathrm{~Bq} / \mathrm{kg}$. Hasil selengkapnya dapat dilihat pada Tabel 1.

Tabel 1. Nilai Aktivitas Radionuklida Alam
Tabel 1 terlihat bahwa nilai aktivitas masing-masing unsur radionuklida pada tiap stasiunnya sangat fluktuatif, hal ini karena dipengaruhi oleh faktor geologi, geografi dan jarak dengan sumbernya (El-Saharty, 2013). Data di atas menunjukkan nilai radionuklida 40 K memiliki rata-rata aktivitas tertinggi dibanding unsur yang lain yaitu $365,79 \mathrm{~Bq} / \mathrm{kg}$. Hal tersebut sesuai dengan pernyataan Peterson et al., (2007), bahwa radionuklida ${ }^{40 \mathrm{~K}}$ memiliki ketersediaan di alam lebih banyak dibandingkan dengan unsur radionuklida lainnya. Sedangkan radioaktivitas ${ }^{226} \mathrm{Ra}$ memiliki nilai paling rendah yaitu $76,70 \mathrm{~Bq} / \mathrm{kg}$. Hal ini sama seperti yang terjadi di southwestern Nigeria, dimana kandungan ${ }^{226 \mathrm{Ra}} \mathrm{di}$ soil, rock, clay, sedimen dan food crop samples adalah paling rendah dibanding dengan unsur yang lain (Jibiri et al., 2016). Rendahnya aktivitas $226 \mathrm{Ra}$ dipengaruhi oleh sifat kimia dari unsur tersebut. Prihatiningsih dan Suseno (2012) menjelaskan, bahwa $226 \mathrm{Ra}$ lebih mudah lepas dari matriks sedimen dibandingkan dengan ${ }^{40} \mathrm{~K},{ }^{212} \mathrm{~Pb}$ dan ${ }^{228} \mathrm{AC}$. Fenomena tersebut juga sama dengan yang terjadi di Iran dimana nilai rata-rata aktifitas untuk ${ }^{40 \mathrm{~K}},{ }^{226} \mathrm{Ra}$ dan ${ }^{232} \mathrm{Th}$ di soil dan terrestrial secara berturut-turut adalah $457,7 \mathrm{~Bq} / \mathrm{kg} ; 24,3$ $\mathrm{Bq} / \mathrm{kg}$ dan $25,8 \mathrm{~Bq} / \mathrm{kg}$ (Kardan et al., 2017). Terlihat nilai aktivitas ${ }^{40} \mathrm{~K}$ di perairan Sluke $(365,79 \mathrm{~Bq} / \mathrm{kg})$ jauh lebih rendah dari yang ada di Iran $(457,7 \mathrm{~Bq} / \mathrm{kg})$, hal ini dimungkinkan karena ${ }^{40} \mathrm{~K}$ yang ada di perairan Sluke banyak yang terlarut di perairan. Sedangkan nilai aktivitas ${ }^{226} \mathrm{Ra}$ di periran Sluke $(76,70 \mathrm{~Bq} / \mathrm{kg})$ lebih tinggi dari yang ada di Iran $(24.3 \mathrm{~Bq} / \mathrm{kg})$ hal ini dimungkinkan di sedimen periaran Sluke ada sumber ${ }^{226}$ Ra.

\begin{tabular}{|c|c|c|c|c|c|c|}
\hline \multirow{2}{*}{ Stasiun } & \multicolumn{2}{|c|}{ Koordinat } & \multicolumn{4}{|c|}{ Aktivitas $(\mathrm{Bq} / \mathrm{kg})$} \\
\hline & BT & LS & $40 \mathrm{~K}$ & $212 \mathrm{~Pb}$ & $226 \mathrm{Ra}$ & ${ }^{228} \mathrm{AC}$ \\
\hline 1. & $111046^{\prime} 73^{\prime \prime}$ & 6063'92'" & 237,10 & 162,54 & 83,71 & 194,53 \\
\hline 2. & $1111^{\circ} 46^{\prime} 42^{\prime \prime}$ & $6 \circ 63^{\prime} 56^{\prime \prime}$ & 378,97 & 145,80 & 74,81 & 212,23 \\
\hline 3. & $111046^{\prime} 81^{\prime \prime}$ & 6063'32'" & 349,84 & 156,51 & 67,17 & 205,53 \\
\hline 4. & $111046^{\prime} 24^{\prime \prime}$ & 6062'69'" & 414,08 & 146,55 & 77,59 & 190,48 \\
\hline 5. & $111046^{\prime} 38^{\prime \prime}$ & $6062^{\prime} 39^{\prime \prime}$ & 503,87 & 333,34 & 83,6 & 466,46 \\
\hline 6. & $111046^{\prime} 48^{\prime \prime}$ & $6 \circ 62^{\prime} 47^{\prime \prime}$ & 456,40 & 128,61 & 70,12 & 165,50 \\
\hline 7. & $111047^{\prime} 46^{\prime \prime}$ & 6062'34'" & 414,51 & 166,59 & 71,93 & 226,56 \\
\hline 8. & $111047^{\prime 23 ' "}$ & 6062'78'" & 376,84 & 88,62 & 66,07 & 95,30 \\
\hline 9. & $111047^{\prime} 64^{\prime \prime}$ & 6062'98'" & 160,54 & 129,59 & 95,24 & 187,55 \\
\hline \multicolumn{3}{|c|}{ Rata-rata } & 365,79 & 162,01 & 76,70 & 216,02 \\
\hline
\end{tabular}


Tabel 2. Kedalaman Perairan Sluke Rembang

\begin{tabular}{cccccccccc}
\hline Stasiun & 1 & 2 & 3 & 4 & 5 & 6 & 7 & 8 & 9 \\
$\begin{array}{c}\text { Kedalaman } \\
(\mathrm{m})\end{array}$ & 0,25 & 4,57 & 1,75 & 8,0 & 8,8 & 8,08 & 6,53 & 2,65 & 0,32 \\
\hline
\end{tabular}

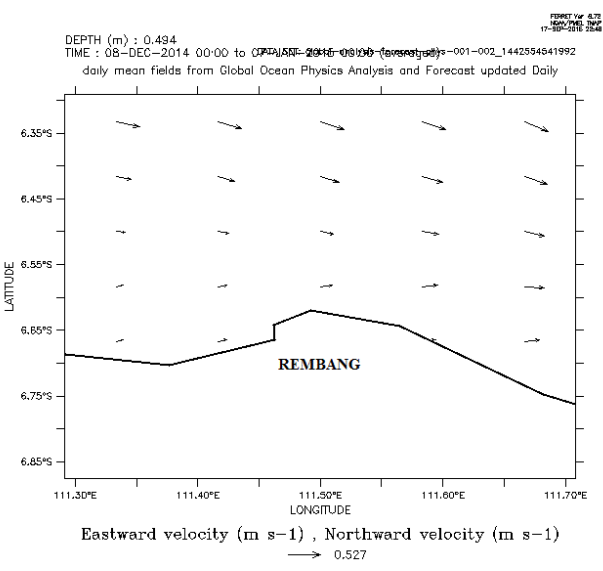

Desember 2014-Januari 2015

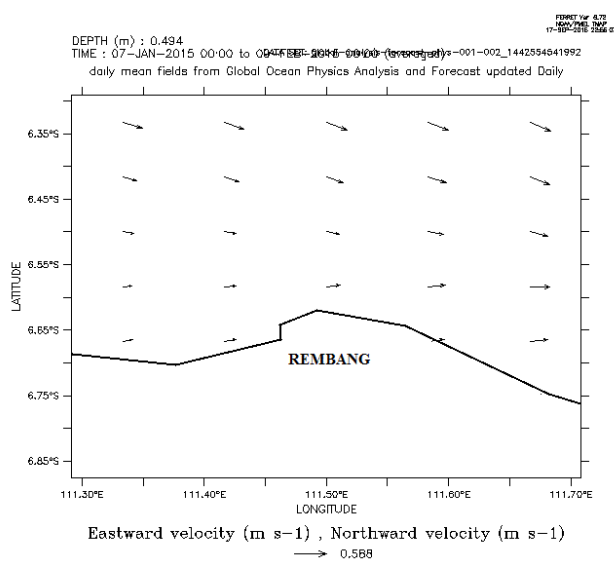

Januari-Februari 2015

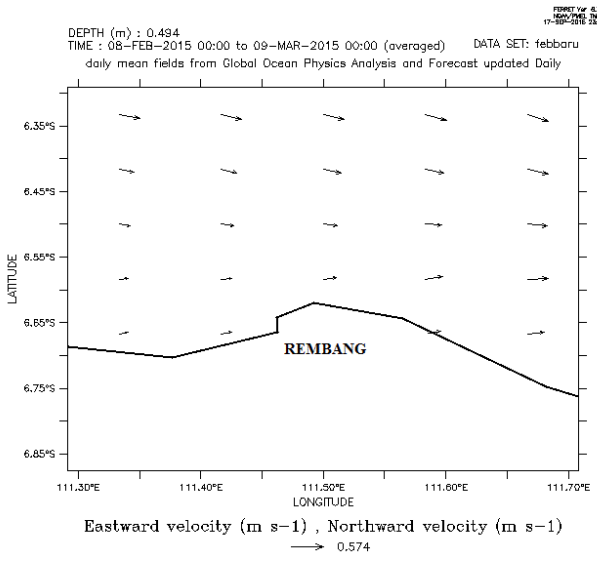

Februari-Maret 2015

Gambar 2. Pola Arus Rata-rata Selama 3 Bulan

Aktivitas radionuklida tertinggi secara keseluruhan berada di stasiun 5, dimana stasiun 5 merupakan stasiun yang dipakai untuk kegiatan pembongkaran muatan batubara dari kapal tongkang. Pada saat berlangsungnya proses pembongkaran akan menyisakan reruntuhan batubara yang jatuh ke perairan yang kemudian berikatan dengan partikel tersuspensi dan terendapkan di dasar laut. Menurut Cooper (2005) , adanya masukan batubara dapat meningkatkan aktivitas naturally occuring radionuclide materials (NORM).

Proses resuspensi dan pengendapan material radionuklida dapat diakibatkan oleh kondisi lingkungan perairan salah satunya yaitu kedalaman perairan. Data kedalaman perairan Sluke ditunjukkan dalam Tabel 2.

Aktivitas ${ }^{40} \mathrm{~K},{ }^{212} \mathrm{~Pb}$ dan ${ }^{228} \mathrm{Ac}$ di stasiun 1 dan 9 memiliki nilai rata-rata aktivitas yang rendah. Hal ini dapat disebabkan karena stasiun 1 dan 9 memiliki kedalaman yang paling dangkal dibandingkan 7 stasiun lainnya. Kecepatan arus yang melewati stasiun 1 dan 9 diduga mampu mengakibatkan pengadukan di perairan dangkal. Menurut Prihatiningsih dan Hudiyono (2013) dan Kurniawan et al., (2014), bahwa kondisi perairan seperti kecepatan arus dan bathimetri mengakibatkan pengadukan secara terus menerus. Pengadukan secara terus-menerus akan mengakibatkan 

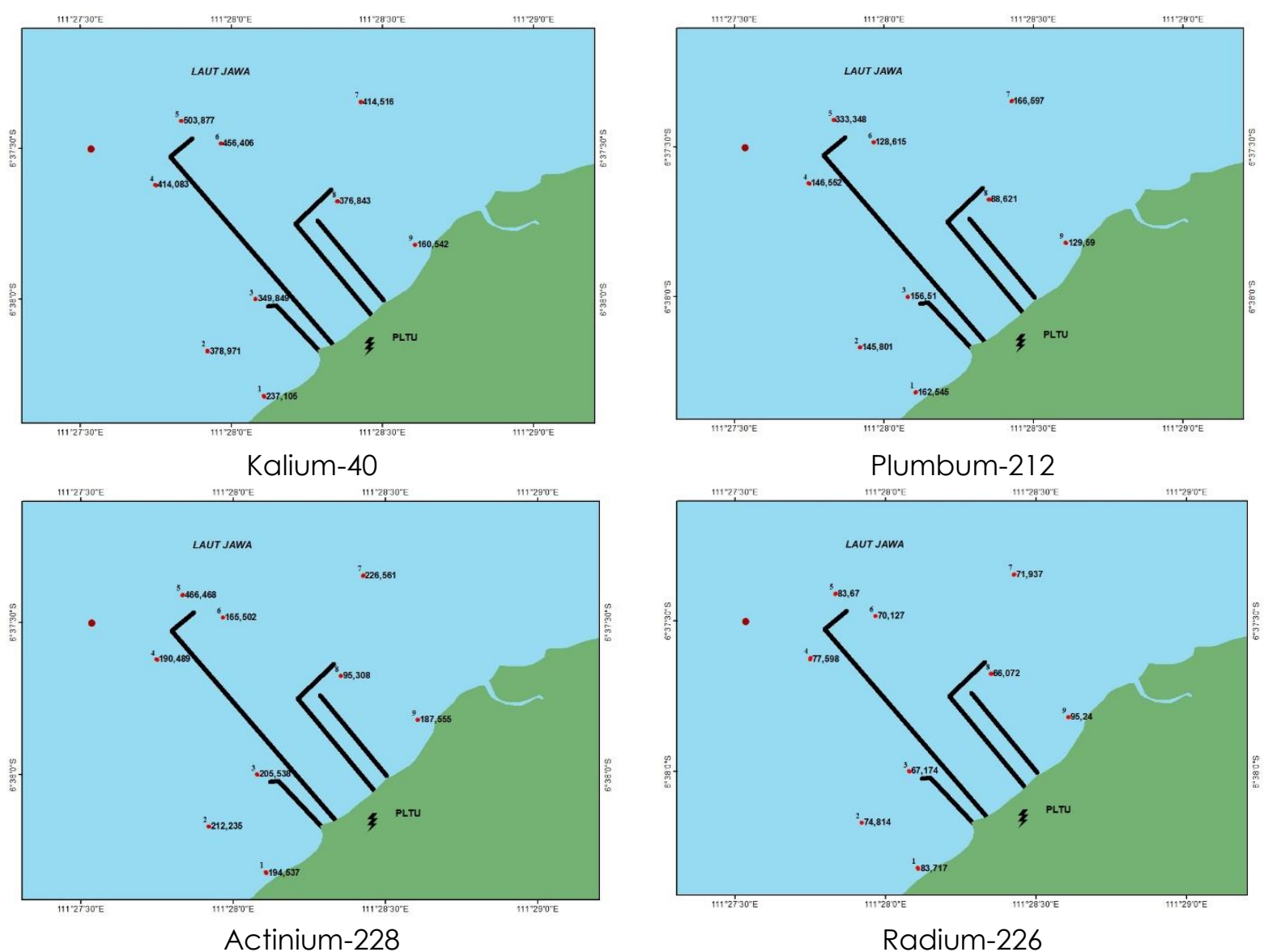

Gambar 3. Sebaran Radionuklida

resuspensi sedimen sehingga dapat melepaskan radionuklida yang terikat pada sedimen bertekstur pasir ke badan air. Pelepasan radionuklida dari sedimen mengakibatkan berkurangnya nilai aktivitas radionuklida di sedimen (Muslim et al., 2015).

Hasil pemodelan arus dari CMEMS (Copernicus Marine Environment Monitoring Service) yang ditampilkan dengan software Ferret ditunjukkan pada Gambar 2a-c yang memperlihatkan pola arus selama 3 bulan dengan pergerakan ke arah timur laut-timurtenggara di perairan Sluke Rembang. Secara keseluruhan arah dan gerakan arus terlihat cenderung bergerak ke arah timur laut.

Berdasarkan pengolahan data arus dengan overlay ke software ArcGIS didapatkan peta sebaran radionuklida (Gambar 3a-d). Pergerakan radionuklida di perairan dipengaruhi oleh sumber radionuklida yang berada di stasiun 5 . Aktivitas radionuklida menyebar dari stasiun 5 menuju stasiun 6 dan 7 sesuai dengan pola arus yang bergerak ke timur laut (Gambar 2a-c) sehingga terjadi perbedaan nilai aktivitas yang berurutan. Pergerakan aktivitas radionuklida juga terjadi pada stasiun $1,2,3$, 4, 8 dan 9 menuju ke stasiun 7 , terbukti nilai aktivitas radionuklida di stasiun 7 lebih besar (Gambar 3a-c). Hal ini sesuai dengan pendapat Perianez (2006), bahwa pergerakan arus mempengaruhi distribusi radionuklida pada lingkungan perairan.

\section{KESIMPULAN}

Berdasarkan uraian tersebut di atas dapat disimpulkan bahwa aktivitas radionuklida ${ }^{40} \mathrm{~K},{ }^{212} \mathrm{~Pb},{ }^{226} \mathrm{Ra}$ dan ${ }^{228} \mathrm{Ac}$ yang terkandung di sedimen di perairan Sluke Rembang memiliki aktivitas secara berturutturut dari 160,54-503,87 Bq/Kg; 88,62-333,34 $\mathrm{Bq} / \mathrm{Kg} ; \quad 66,07-95,24 \mathrm{~Bq} / \mathrm{Kg}$ dan 95,30-466,46 $\mathrm{Bq} / \mathrm{Kg}$. Sebaran radionuklida alam di perairan Sluke Rembang dipengaruhi oleh topografi, sumbernya dan pola arus yang bergerak ke timur laut. 


\section{DAFTAR PUSTAKA}

Coles, D.G., Ragaini, R.C. \& Ondov, J.M. 1978. Behaviour of Natural Radionuclides in Western Coal-Tired Power Plants. Environ. Sci. Technol., 12 (4):442-446. doi: 10.1021/es60140a007

Copper, M.B. 2005. Naturally Occuring Radioactive Materials (NORM) in Australian Industries-Review of Current Inventories and Future Generation. Enviroment Radinonuclide Services Pty. Ltd.

Djarwanto, P.S \& Subagyo, P. 1998. Statistik Induktif. BPFE, Yogyakarta.

El-Saharty, A.A., 2013. Radioactive Survey of Coastal Water and Sediments Across Alexandria and Rashid Coasts. Egypt. J. Aquat. Res, 39:21-30. doi: 10.1016/j.ejar. 2013.02.001

El-Taher, A. \& Madkour, H.A. 2011. Distribution and Environmental Impacts of Metals and Natural Radionuclides in Marine Sediments in-Front of Different Wadies Mouth Along the Egyptian Red Sea Coast. Appl. Radiat. Isot. 69:550-558. doi: 10.1016/j.apradiso.2010.11.010

Jibiri, N.N., Isinkaye, M.O., Bello, I.A. \& Olaniyi, P.G. 2016. Dose Assessments from the Measured Radioactivity in Soil, Rock, Clay, Sediment and Food Crop Samples of an Elevated Radiation Area in SouthWestern Nigeria. Environ. Earth. Sci., 75(2):107-120. doi: 10.1007/s12665-015-481 9-3

Kardan, M.R., Fathabdi, N., Attarilar, A., Esmaeili-Gheshlaghi, M.T., Karimi, M., Najafi, A. \& Hosseini, S.S. 2017. A National Survey of Natural Radionuclides in Soils and Terrestrial Radiation Exposure in Iran. J. Environ. Radioact, 178-179:168-176. DOI: 10.1016/j.jenvrad.2017.08.010

Kurniawan, S., Muslim \& Suseno, H.. 2014. Studi Kandungan Radionuklida Cesium-137 ( $\left.{ }^{137} \mathrm{Cs}\right)$ dalam Sedimen di Perairan Semenanjung Muria Kabupaten Jepara. J.I Oseano., 3(1):67-73.

Maher, O.E \& Saleh, R.M.A. 2007. Radiation Measurements in Soil in the Middle of Gaza-Strip Using Different Type of Detectors. J. Ser. Nat. Stud. Eng. 15: 23-37.
Modesta, F. 2008. PLTU Rembang Masa Depan Listrik Nasional. http:// modestafiska.wordpress.com.

Muslim., Suseno, H. \& Rafsani, F., 2015. Distribution of ${ }^{137} \mathrm{Cs}$ Radionuclide in Industrial Wastes Effluents of Gresik, East Java, Indonesia. Atom Indonesia. 41 (1): 47-50. doi: 10.17146/aij.2015.355

Perianez, R. 2006. Modelling the Dispersion of Radionuclides in the Marine Environment: An Introduction. Springer. DOI: 10.1007/b138979

Peterson, J., Macdonell, M., Haroun, L. \& Monette, F. 2007. Radiological and Chemical Fact Sheets to Support Risk Analyses Contaminated Areas., Argonne National Laboratory Environmental Science Division. U.S.Department of Energy.

Poerbandono \& Djunasjah, E. 2005. Survei Hidrooseanografi. Refika Aditama, Bandung.

Prihatiningsih, W.R. \& Suseno, H.. 2012. Status Konsentrasi ${ }^{232} \mathrm{Th}$ dan ${ }^{226} \mathrm{Ra}$ dalam Sedimen Pesisir Pulau Bangka. Jurnal Teknologi Pengelolaan Limbah, 15(2):6570.

Prihatiningsih, W. R dan S. Hudiyono. 2013. Radioekologi Kelautan di Semenanjung Muria : Studi Distribusi dan Prilaku Radionuklida Ra-226, Ra-228 dan K-40 di Perairan Pesisir, Prosiding Seminar Nasional Teknologi Pengelolaan Limbah IX Pusat Teknologi Limbah RadioaktifBATAN Fakultas Teknik Universitas Sultan Ageng Tirtayasa: 303-309.

Sihono., Sutanto, W.W. \& Iswantoro. 2012. Radioaktivitas PM 2,5 dan PM 10 di Lokasi PLTU Rembang. Prosiding PTAPB-BATAN, Yogyakarta.

UNSCEAR. 2008. Sources and Effects of Ionizing Radiation. Report of the United Nations Scientific Committee on the Effects of Atomic Radiation to the General Assembly, United Nations, New York, USA

Uslu, I. \& Gokmese, F.. 2010. Coal an Impure Fuel Source: Radiation Effects of Coalfired Power Plants in Turkey. Hacettepe J. Biol. Chem., 38(4):259-268. 